\title{
The Perceived Impact of the Postgraduate Diploma in Higher Education and Training as an Academic Development intervention in an Institution of Higher Learning
}

\author{
Vuyisile Nkonki
}

vnkonki@ufh.ac.za

Linda Scheckle

Ischeckle@ufh.ac.za

Nombulelo Jonas

njonas@ufh.ac.za

\section{Siyanda Ntlabathi}

sntlabathi@ufh.ac.za

Alanna Riley

ARiley@ufh.ac.za

Patricia Muhuro

PMuhuro@ufh.ac.za

University of Fort Hare

Doi:10.5901/mjss.2014.v5n11p157

\section{Abstract}

Following mixed views in literature on the relevance and return on investment of formal higher education professional development initiatives, the current study sought the views of the impact of the Postgraduate Diploma in Higher Education and Training (PGDHET) on the professional practice of higher education staff in one institution. Framed in the interpretive paradigm, the study adopted a case study design in which multiple sources of data were utilised. Data were collected through an open-ended questionnaire from eleven (11) purposefully selected lecturers possessing a PGDHET qualification. The data was corroborated with a data analysis of PGDHET reports. Qualitative data thus collected was analysed through the extraction and aggregation of meaning units into themes. Quantitative data was used to discern and describe impact trends of the PGDHET. It emerged from the study that the PGDHET challenged lecturers' conceptions of teaching and learning, and expanded their repertoire of innovative teaching strategies. Furthermore, participants reported contributions to advancement of departmental best teaching practices and the status of teaching institutionally. The conclusion drawn is that the PGDHET impacts beyond the lecture room as it influences also the academic development practices, faculty and departmental practices, as well as the overall culture of the institution. This research recommends ways of further consolidating and further advancing the impact of the PGDHET.

Keywords: Postgraduate Diploma in Higher Education and Training, Perceived Impact, Academic Development, Professional Development.

\section{Introduction}

This paper on the perceived impact of the Postgraduate Diploma in Higher Education and Training (PGDHET) is commenced against the background of the plethora of teaching development programmes initiated in a particular institution, arising out of the recommendations from a wave of quality assurance audits and reviews, as well as the quality enhancement projects instituted by the Department of Higher Education and Training (DoHET). There are other 
imperatives such as the concern for academic standards, quality of course offerings, and the effectiveness of teaching which students consider when choosing institutions and programmes. Hence the need to improve and further develop teaching practices of academics in institutions of higher learning arises from the above. Questions have to be asked about the impact of these teaching development interventions since there is also a concern about return on investment for funds invested in teaching development initiatives, both by the institution and the national Directorate of Teaching Development.

This particular study focused on the Postgraduate Diploma in Higher Education and Training (PGDHET), a formal teaching qualification for university lecturers, as a teaching development initiative instituted by the Teaching and Learning Centre (TLC) in an institution of higher learning. According to Ball and Cohen (1999), formal teaching qualifications for higher education lecturers sprang out of the need for professional learning for instructional purposes, and the need for a theory that underlies teaching practices. Similarly, the purposes of the Post-Graduate Diploma in Higher Education \& Training (PGDHET) are to:

- facilitate the professional development of lecturers in higher education by developing their knowledge of Higher Education (HE) as a field of study.

- assist them to enhance their ability to facilitate, manage and assess learners' learning.

- provide professional accreditation for HE practitioners (Post-graduate Diploma in Higher Education and Training Course Guide, 2012:3).

The above purpose statement articulates well with the professional development imperatives of providing lecturers with the knowledge, skills, and competencies that would enable them to be effective teaching and learning practitioners that benefit their students. The PGDHET programme and its processes involve the juxtaposition of disciplinary knowledge, practical experiences, and substantive problems of teaching and learning practice. It also involves the exploration of a range of considered "best practices", trying out new things, and documenting experiences with these innovations.

Guskey (2002) believes that lecturers who take up professional development are motivated by the pragmatic beliefs that it will expand their repertoire of knowledge and skills, and their effectiveness, since it will provide them with specific, concrete, and practical ideas on how to deal with substantive teaching and learning challenges encountered in the lecture rooms. In this vein, the PGDHET programme is designed such that it equips lectures with the knowledge of the theory that foregrounds curriculum development, assessment, teaching and learning practices. The course also requires that lecturers reflect on what they do by using theory thus acquired to mirror their own teaching practices, make the necessary adjustments that should help improve on their teaching practices and make them effective teaching and learning practitioners. All modules of the PGDHET are assessed by means of a Portfolio of Evidence (PoE) where participants' demonstrate abilities to articulate their teaching philosophies, foreground their teaching practices, collect evidence about what works (evidence based teaching), and use of a variety of lenses to evaluate their own teaching practices.

Apparently, research on the impact of PGDHET or Post Graduate Certificate in Higher Education (PGCHE ) as it is called in other contexts, is warranted since there is acknowledgement that this area is under-researched (Parsons, Hill, Holland, and Willis, 2013; McAlpine, 2003). Even in contexts where research has been conducted, the PGDHET is viewed as having limited impact on university staff (Parsons et al., 2013). The reasons for conflicting results include methodological issues associated with earlier impact studies, and the contexts in which those studies were conducted (Gibbs and Coffey, 2004).

\section{Literature Review}

Studies on teaching development initiatives suggest that there is no agreement as to which models of Professional Development for Higher Education teaching are the most effective. Butcher and Stoncel (2011) argue that Teacher Professional Development models are varied and contested. For example, Parsons, Hill, Holland, and Willis (2013) distinguish between non-qualification approaches and the formalised qualification approaches. The diverse range of programmes include part-time and certificated programmes, block and intensive workshops, seminars and colloquia, mentoring arrangements and agreements, observation-based videos and micro-teaching. Ball and Cohen (1999) argue that staff development workshops lack substance as they are "intellectually superficial and disconnected from deep issues of curriculum and learning". The cultural diversity of lecturers and students, and the wide range of disciplinary orientations (Butcher and Stoncel, 2011), determine whether these teaching development initiatives either take the generic development approaches or disciplinary-based approaches in terms of interaction levels, context and culture (Gibbs, 2012; Van Keulen, 2009)). The extent to which interventions and the actual teaching behaviours are aligned is 
dependent on the professional development approach taken. There are also some arguments about some form of individualisation in the offering of teaching development programmes which should influence changes at departmental level (Knight and Trowler, 2001).

Clement and Vandenberghe (2000) argue for the "orienting theory" that provides a good basis for professional development. Blackmore and Blackwell (2006) argue that both individuals and the institution should and could learn from these formal programmes. They further suggest that Academic Development leaders and practitioners must surely base part of their claim to be professional upon expert knowledge disseminated through a formalised professional development intervention. With respect to the PGDHET in particular, the benefits of professional development are reported as relating to change in the conceptions of teaching and learning; enhancing dialogue among colleagues; increased alignment towards innovative teaching strategies (Butcher and Stoncel, 2011). Other studies like Sadler (2013) suggest that the PGCHE help new staff gain confidence in teaching approaches, and also assist them in the formation of professional identities. The acquisition of key concepts related to teaching and learning which had profound implications for teaching practices is viewed by Kandlbinder and Peseta (2009) as an important step in the conceptualisation and grounding of one's teaching practices. The following concepts, namely reflective practice, constructive alignment, student centred approaches to learning, Scholarship of Teaching and Learning, and assessment driven learning were identified as key concepts that shaped teaching practice of participants who went through the Postgraduate Certificate in Higher Education Teaching and Learning. The same authors reveal that the actualisation of these concepts is impacted on negatively by the language and rules of disciplines, difficulty in seeing complexity in the concepts, relevance of these concepts to teaching practice, and the problem of time. Parsons, et al (2013) argue that there is no substantive evidence to suggest impacts on the teaching practices as a direct translation of the changed attitudes, conceptions, and acquired knowledge and skills. With respect to changes in teachers' conceptions of teaching and learning, Gibbs and Coffey (2004) noted claims from the self reports of the teachers interviewed who purported to have changed from teacher focused to student focused approaches to teaching.

Parsons, et al (2013) note that there are limited impact studies on teaching development programmes, with more studies focusing on programme development and programme delivery. Where studies of impact have been conducted, there is seemingly inconclusive evidence about the positive effects of teaching development programmes owing to fragmented evidence base and lack of coherence (McAlpine, 2003). Brew and Boud (1995) concur and further suggest that results on the effects of professional development to learning are inconclusive. Guskey (2002) also notes the ineffectiveness of most teaching development programmes as suggested by a number of professional development research reviewed. There is also a lament about the lack of methodological rigour in studies that sought to look into the impact of teaching development programmes owing to their heavy reliance on self reports (Gibbs and Coffey, 2004; Parsons, Hill, Holland, Willis, 2013). Other criticism involves the documentation of the effects rather than the changes brought about by PGDCHE participation. Also, there is an outcry about how sustained are the claimed effects of professional development interventions since most studies of impact are small-scale measures taken immediately after the completion of the course or intervention. The above criticism creates the need for more impact studies on the PGDHET, so that more evidence is brought to bear on the impact of the PGDHET.

\section{Theoretical Framework}

The theoretical framework for this study focused on the conceptualisation of impact as it relates to academic development programmes. Gray and Radloff (2008) posit that impact is often associated with a variety of qualitatively nuanced words for evaluating academic development, namely: achievement, accomplishment, change, consequence, contribution, difference, effect, impression, influence, outcome, output, results, success, et cetera. The impact determinants gleaned from studies of impact of teaching development programmes are classified by Parsons, et al (2013) into six areas, namely: impact on teachers' attitudes, knowledge and skills, impact on teachers' behaviour and practice, effects on disciplinary or generic programme focus, effects of compulsory and/or voluntary participation, impact on the students' learning experience and other impacts. Other studies of impact make use of Kreber and Brook's (2001) framework which assesses impact on six levels, namely: participants' perceptions and satisfaction with a programme; participants' beliefs about teaching and learning; participants' teaching performance; students' perceptions of staff's teaching performance; students' learning; and the culture of the institution.

Butcher and Stoncel (2012) consider frameworks that have been used to study impact that occurs at the level of the organisation, the department, the experience of students taught by the participants, the careers of participants, and the individual participants. Whereas, Guskey (2000) conceptualises impact at various levels, namely: participants' reactions, participants' learning, organisational support and change, participants' use of new knowledge and skills, and 
students' learning outcomes. With respect to teaching development programmes, Guskey (2002) argues that the impact of professional development takes a particular sequence, whereby teachers' attitudes and beliefs are as a result of improvement in students' learning outcomes following successful implementation of teaching practices. Since there are areas of convergence between the frameworks reviewed, our conceptualisation of impact as it relates to the Postgraduate Diploma in Higher Education and Training (PGDHET) considered and borrowed ideas from all the above frameworks.

\section{Statement of the Problem}

Notwithstanding the potential effects of the PGCHE and the criticism levelled against past impact studies conducted, this research sought to bring new evidence to bear on this issue of the impact of a formal teaching development qualification for university lecturers. In this particular study we argue that the impact of the PGDHET extends beyond individual academics in the confines of the lecture room and includes impact at departmental and institutional levels. Also, we argue that the impact of the PGDHET extends to the grounding of practices of teaching development practitioners in the Academic Development Centre. The uniqueness of the study stems from multiple perspectives (lecturers and academic development practitioners) and multiple sources of data (self reports and documents) rather than reliance on self reports only.

\section{Research Question}

What is the perceived impact of the Postgraduate Diploma in Higher Education and Training as an academic development strategy at an institution of higher learning?

\section{Research Methodology}

\subsection{Research paradigm}

This study employed the interpretive perspective. Interpretive or constructivist researchers tend to rely on the participants' views of the situation being studied. They recognise the impact on the research of their own background and experiences (Mackenzie and Knipe, 2006). They also rely on qualitative data collection methods and analysis, or a combination of both qualitative and quantitative methods. Quantitative data may be utilised in a way, which supports or expands upon qualitative data and effectively deepens the description.

\subsection{Research Design}

The study adopted a case study design in which graduates of the PGDHET, as well as the PGDHET reports, constituted the cases of this particular case study. Leedy and Ormrod (2005) define a case as an individual, programme, event or intervention which can promote understanding or inform practice for similar situations. This case study was conducted to isolate themes common to all cases in the general group, namely PGDHET graduates; themes common to sub-groups, namely lecturers, academic development practitioners, and programme managers; and features that are unique to specific cases (Struwig and Stead, 2001). The case study allows for the interrogation of documents and other extensive data on the programme or event on which the investigation is focused. In this case, the study made use of self reports from interviews with the PGDHET graduates as well as the PGDHET reports.

\subsection{Population and Sampling}

All the PGDHET graduates in the employ of the institution from which this research is conducted constituted the population. The sample was composed of twelve purposefully selected participants whose views on their perceptions of the impact of the PGDHET were canvassed. Cohen, Manion, and Lawrence (2007) maintain that purposeful sampling selects participants on the basis of their possession of a particular characteristic being sought. In this particular research possession of the PGDHET was the inclusion criterion. 


\subsection{Data Collection Instruments}

The PGDHET graduates sampled were asked to respond to an open-ended questionnaire which solicited views on their perceptions of the impact of the PGDHET. The participants were asked to comment on the benefits for one's teaching, significant changes in participants' teaching practices, as a result of the insights gained from the PGDHET, and how these insights informed, influenced and shaped practices in the participants' Faculty and/or department. Further, data was collected from documents, namely: the PGDHET moderation cum review reports, and the PGDHET quarterly reports.

\subsection{Data Analysis}

The transcript generated from the responses from the open-ended questionnaires formed the data for this particular study. The content analysis method of analysing qualitative data was employed. This involved looking for meaning units, that is, words, short phrases or sentences that communicate a particular view (Struwig and Stead, 2001). The consistencies and the differences within the meaning units were later used to identify themes which were later organised into the preset categories suggested by the adapted and adopted impact framework (Jansen, 2010). Further, data from the reports was extracted, and later used to support each of the themes and categories suggested by adopted analytic framework. Below, are the narratives of themes and sub-themes of each category with profound or representative quotes embedded.

\section{Results/Findings}

When participants who graduated with the PGDHET were asked for their perceptions on the impact of the PGDHET on their practices, results show that candidates benefitted from the programme. The expressed and assessed responses of the PGDHET graduates on the impact of the PGDHET are summarised and categorised into the levels of impact below:

\subsection{Participants' perceptions of the PGDHET programme}

The PGDHET helped to develop conscientiousness in the teaching practices of the participants as it challenged them to "hold oneself accountable for revisiting one's teaching practices" and challenged them to "act on the development and improvement of teaching and learning". The manner in which sessions are organised and conducted influenced participants' perceptions of the PGDHET programme as a professional development initiative. One of the participants opined that

"Personally, I found that working as a group provided different perspectives and new ways of thinking about teaching and learning".

Engaging with the modules of the PGDHET also exposed participants to the HET context which was an unfamiliar terrain for some. The programme provided a holistic perspective of teaching and learning, theory underpinning their practice, teaching and learning models, policies, and methodologies, thereby improving their programmes and service delivery. Other participants indicated that

"the PGDHET helped participants to understand the changes in the teaching learning context in S.A. [South Africa] and globally".

It also provided an opportunity for the participants to reflect on their current practices, and consolidated participants' understanding of teaching, learning and assessment.

\subsection{Participants' beliefs about teaching and learning}

Participants appreciate the fact that the PGDHET impressed the need to act on the development and improvement of their teaching and learning. Participants came to believe that teaching and learning should be seen as an art that must be developed. For some, the PGDHET helped to "formalise thinking" and enabled some to "have a stance on teaching". Conceptualising one's own teaching practices was a significant gain for some, enabled by the acquisition of frames and concepts. The following quote represent the above sentiment 
"I have been exposed to the different paradigms and concepts of the educational field and it has been most interesting to find out where my style of lecturing fits in - something I have never thought about".

The theoretical aspect of the course made them read, reflect more deeply and account for their actions. In the sessions, participants' thinking and beliefs about teaching and learning are searched and interrogated resulting in the reconsideration of one's stance on teaching. One of the participants reflected as follows:

"Articulating my teaching philosophy revealed a great deal of misconceptions that I had to discard. I have undergone a transformation that would have never happened had I not registered with the programme".

\subsection{Participants' teaching practices}

Compiling the teaching portfolio helped some to action the definition of 'good practice' by providing evidence of practice. The PGDHET presented a good way of holding oneself accountable for revisiting one's existing teaching practices and of implementing new techniques to enhance student learning. Compiling a teaching portfolio has been a great developmental and empowering experience, as some claim that it prompted them to reflect and improve their performance as lecturers in several ways. The PGDHET expanded the repertoire of teaching strategies for some. For other participants it consolidated and expanded their teaching philosophies. One of the participants commented that

"The PGD helped inform our teaching and learning model, policies, and methodologies... thereby improving our programmes... The PGD encouraged a shift to a more developmental model".

Others indicated that they have gained confidence, professional identity, and self belief as teachers as a result of having gone through the PGDHET. This is evidenced by the following sentiments:

"it has made me to feel confident in my class pedagogical endeavours" and "holding a PGDHET means a lot to me because it is a value laden qualification. I feel confident to be in class as a holder of the qualification.

The above statement expresses self-belief and a sense of professional identity on the part of teaching practitioners who have developed their teaching competencies.

\subsection{Enhancing students' learning}

The sample used for the impact study, that is, the graduates of the programme claim that the PGDHET has empowered them to enhance students' learning. One of the participants remarked that

"...the PGDHET has had a direct and positive benefit to my students whom I know, have an even better understanding of, and whom I strive to ensure that my teaching practices will optimally empower."

The value of using students' evaluation data to adjust one's teaching is appraised in the following sentiment echoed by one of the participants.

"Perhaps, the biggest change was to introduce a formal evaluation of my teaching by my students and learn how to meet each cohort's particular needs".

Participants of the PGDHET had to experience firsthand, the use-value of e-learning in the enhancement of learning and teaching. Otherwise, the PGDHET cannot justify its professional development mandate if it cannot lead and show that it embraces blended learning and various modes of delivery. The PGDHET reports suggested that all the PGDHET facilitators have their courses enrolled on Blackboard. Materials and resources used for the course, discussions, conversations, assessment tasks, and notices are posted on Blackboard. Thus, Blackboard is used for the improvement of transmission as well as the transactional models of teaching and learning.

\subsection{Contribution to the Faculty or Department}

The PGDHET graduates have become the proverbial yeast in their respective faculties and departments. Some of the 
PGDHET graduates claim that they have been very influential in the departments and faculties. One of the participants revealed that

"I find the number of academic staff enrolled for the PGDHET worrying and this is one of the main reasons why I have been very 'verbal' in terms of the benefits of the programme. I am hoping that my optimistic frame of mind about this programme will rub off on more of my colleagues".

Though there are not very obvious changes at departmental level, but the seed has been planted. Some indicated that they were able to complete their portfolios, whereas, others in their Faculties had not managed to do so. Some encourage members of the Faculty to keep journals and evidence. At course/module level, the changes are claimed to have been significant. For instance, one of the PGDHET graduates purported that

"much effort has gone into ensuring that the objectives are clearly stated, the content is selected and pitched appropriately, the teaching methods are informed by the diverse nature of the students, and that there is alignment between assessment tasks and learning outcomes".

There are reports by some participants that it benefitted the curriculum renewal and re-curriculation processes of their departments. One of the participants reported on the development and productivity of the department, in the following way:

"PGDHET is beneficial in terms of aligning their assessment tasks by using action verbs that go with particular NQF levels, and by ensuring that they align the assessment criteria to the learning outcomes."

The impact of the PGDHET on the entire department seems to be significant when staff learn as a department. This is vital for the development of department-specific philosophy and norms, as captured in the following sentiment expressed by one of the participants:

"Registering a number of staff members per department for the diploma actually helps you to learn as a department because it promotes an overall understanding of the department's and/or faculty's definition of 'good teaching' practice".

\subsection{Impact on the Teaching Development Practitioners}

Personal growth on the part of the Academic Development practitioners is claimed to be one of benefits attributed to the PGDHET. One of the participants remarked that

"The diploma...resulted in my personal growth as a teaching development consultant as I have been able to transfer some of the knowledge I gained to the other colleagues in the university through workshops"

One of the teaching development practitioners reported to have gained confidence in his advisory and developmental engagements with lecturers in the faculties around teaching and learning. He opined that

"the diploma gave me confidence in preparing presentations on teaching and learning issues for presentation at staff workshops in the faculties".

The PGDHET's role in the professionalisation of higher education is captured in the following quote:

"...we as lecturers at an institution of higher education need to professionalise..." "...as a consultant in the Teaching and Learning Centre which offers the PGDHET, I felt it necessary to...set the example".

The above quote shows the need for professional development to be cascaded to the whole institution.

\section{Discussion}

The findings of this research lend credence to Van Keulen (2009) and Blackmore and Blackwell (2006) assertions that those who enrol for the formal programme in the form of the PGDHET, voluntarily, derive benefits that help them become effective teachers. The findings on the participants' understanding of the teaching context, and the perspectives for reflection provided by the PGDHET, are consistent with Butcher and Stoncel's (2009) findings on the positiveness and 
open willingness of participants to reflect on effective teaching practices. The development of the consciousness of accounting for one's teaching practices in the session discussions, expressed by the participants, finds explanation from Clement and Vandenberghe (2000) who argue that the sharing of ideas is a good basis for professional development.

Claims by the participants on the conceptualisation of their teaching practices, the formalisation of their thinking about teaching and learning, provide evidence of the actualisation of educational concepts. These claims refute Kandelbinder and Paseta's (2009) findings that key educational concepts were found to be complex and irrelevant in some disciplinary contexts. Again, the findings on the development of one's stance on teaching, and the resultant articulation of one's teaching philosophy support Clement and Vandenberghe's (2000) argument for an "orienting theory" that guides and directs one's teaching. Claims of changes in teaching approaches reported by Gibbs and Coffey (2004) are confirmed by the findings of this research on the acquisition of a repertoire of teaching strategies, and the shift to a more developmental stance to teaching.

The findings align to assertions by Butcher and Stoncel (2011) that a sense of confidence and self belief when teaching can be attributed to lecturers' changes in conceptual understanding, sense of professional identity, the use of pedagogic approaches, and engagement with wider teaching community, and that these were found to be developing confidence on the part of PGCHE participants. Better understanding of students' learning, and how to address particular cohort's needs, as well as the enhancement of students' learning experiences are some of the benefits for students derived from knowledge and insight gained from the PGDHET. Findings on the confidence in engagements with staff on teaching advisory, and departmental matters, personal growth of academic development practitioners, are consistent with Sadler's (2013) findings. These views also confirm Butcher and Stoncel's (2011) views on the development of a pedagogic identity as a result of the PGDHET.

Knight and Trowler's (2009) assertion that change needs to occur at departmental level is confirmed by claims of alignments and adjustments on programmes and plans, articulation of programme philosophies, and learning and defining of good teaching by departments. Being verbal in influencing departments and faculties is enabled by the acquisition of a "teaching voice" which is necessary to influence departmental changes (Butcher and Stoncel, 2011). Thus, the PGDHET is claimed to have provided participants with a teaching voice.

\section{Conclusions}

The study concludes that the PGDHET impacts on the conceptualisation of one's teaching practices leading to the formalisation of one's thinking about teaching practices, and the formulation of one's theory or philosophy of teaching which guides and directs one's teaching activities. We also conclude that the acquisition of key concepts around teaching and learning enable both lecturers and academic development practitioners to have a voice which they use to further engage in the innovation of teaching development activities. Thus, the notion of irrelevance and impracticability of educational concepts is dispelled by the findings of this research. As outlined in the findings, we conclude that the PGDHET has had a tremendous impact on many areas of academic development, such as creating an awareness of one's teaching practices, development of self confidence, the enhancement of the student learning, and the realisation by the PGDHET participants that teaching should be a scholarly act that involves gathering evidence about what works. Also, the study concludes that the PGDHET impacts beyond the lecture room as it influences the activities of academic development practices, faculty and departmental practices, as well as the overall culture of the institution.

\section{Recommendations}

These research findings point out areas of impact that need to be consolidated and further developed. Surely, there is a need to gather more evidence on the enhancement of students' learning, and the achievement of positive learning outcomes on the part of the students as a result of their lecturers having gone through the PGDHET. We further recommend the cascading of the PGDHET to all lecturers and academic developers so that they too can benefit from the knowledge and insight gained from the PGDHET. For further research we would recommend looking at how other PGDHET programmes in other Higher Education Institutions impact on teaching and learning practices, and how the findings of this research could be integrated into the PGDHET programmes so as to improve and further develop them.

\section{References}

Ball, D.L., \& Cohen, D.K. (1999). Developing practice, developing practitioners: Towards a practice-based theory of professional development in Teaching as the Learning Profession, 3-32. 
Blackmore, P., \& Blackwell, R. (2006). Strategic leadership in academic development. Studies in Higher Education, 31(03), 373-387.

Brew, A., \& Boud, D. (1995). Teaching and research: establishing the vital link with learning. Higher Education, 29, 261-273.

Butcher, J., \& Stoncel, D. (2012). The impact of a Postgraduate Certificate in Teaching in Higher Education on university lecturers appointed for their professional expertise at a teaching-led university: 'It's made me braver', International Journal for Academic Development, 17(2), 149-162. DOI:10.1080/1360144X.2011.620107. Accessed on line on 20 February 2014 on http://www.tandfonline.com/doi/ abs/10.1080/1360144X.2011.620107\#.UwX7jGKSz84

Clement, M., \& Vandenberghe, R. (2000). Teachers' professional development: a solitary or collegial (ad)venture? Teaching and Teacher Education, 16, 81-101. Pergamon Publishers. Accessed on-line on 10 February 2014 on www.eslevier.com/locate/tate

Cohen, L., Manion, L., \& Morrison, K. (2007). Research Methods in Education. Sixth Edition. Routledge Taylor \& Francis Group: London and New York.

Gibbs, G., \& Coffey, M. (2004). The impact of training of university teachers on their teaching skills, their approach to teaching and the approach to learning of their students. Active learning in higher education, 5(1), 87-100.

Fiedler, R., Mullin, L. \& Finnegan, M. (2009) Portfolios in Context: A Comparative Study in Two Pre-service Teacher Education Programs, Journal of Research on Technology in Education, 42(2), 99-122.

Gray, K., \& Radloff, A. (2008). The idea of impact and its implications for academic development work, International Journal for Academic Development, 13(2), 97-106

Guskey, T.R. (2000). Evaluating Professional Development. Thousand Oaks, California: Corwin Press.

Guskey, T.R. (2002). Professional Development and Teacher Change, Teachers and Teaching: theory and practice, 8 (3), 381-391.

Ho, Watkins, \& Kelly, (2001). The conceptual change approach to improving teaching and learning: an evaluation of a Hong Kong staff development programme. Higher Education, 42, 143-169.

Jansen, H. (2010). "The Logic of Qualitative Survey Research and its Position in the Field of Social Research Methods [63 paragraphs]", Forum Qualitative Sozialforschung/Forum: Qualitative Social Research, 11(2), Art. 11, http://nbn-resolving.de/urn:nbn:de:0114 fqs1002110

Kandlbinder, P., \& Peseta, T. (2009). Key concepts in postgraduate certificates in higher education eaching and learning in Australasia and the United Kingdom, International Journal for Academic Development, 14:1, 19-31. Accessed on-line on 20 February 2014 on http://www.tandfonline.com/doi/abs/10.1080/13601440802659247\#.UwX7FGKSz84

Kreber, C., \& Brook, P. (2001). Impact Evaluation of Educational Development Programmes, International Journal of Academic Development, 6(2), 96-108.

Leedy, P.D., \& Ormrod, J.E. (2005). Practical Research: Planning and Design. (8th ed.). New Jersey: Pearson Merrill Prentice Hall.

Mackenzie, N., \& Knipe, K. (2006). Research Dilemmas: Paradigms, methods and methodology. Issues In Educational Research, 16 (2), $193-205$.

Parsons, D., Hill, I., Holland, J. \& Willis, D. (2013). Impact of teaching development programmes in higher education. The Higher Education Academy. HEA Research series.

Postareff, L., Lindblom-Ylänne, S., \& Nevgi, A. (2007). The effect of pedagogical training on teaching in higher education. Science Direct Teaching and Teacher Education, 23, 557-571.

Postgraduate Diploma in Higher Education and Training Course Guide (2012). Teaching and Learning Centre, University of Fort Hare.

Sadler, I. (2013). The role of self-confidence in learning to teach in higher education, Innovations in Education and Teaching International, 50:2, 157-166. Routledge, Taylor \& Francis. DOI: 10.1080/14703297. Accessed on-line on 20 February 2014 on http://www.tandfonline.com/doi/abs/10.1080/14703297.2012.760777\#.UwX9N2KSz84

Struwig, F.W., \& Stead, G.B. (2001). Planning, designing and reporting research. Maskew Miller Longman: Cape Town.

Trowler, P. \& Knight, P. T. (2000). 'Coming to Know in Higher Education: Theorising Faculty Entry to New Work Contexts'. Higher Education Research and Development, 19(1), 27-42.

Van Keulen, H. (2009). The impact of instructional development in higher education: effects on teachers and students. International Journal for Academic Development, 14:2, 163-165, Routledge, Taylor \& Francis. DOI: 10.1080/13601440902970098. Accessed on-line on 20 February 2014 on http://www.tandfonline.com/doi/abs/10.1080/13601440902970098\#.UwX8T2KSz84 